JOOP 1135-14/10/2009-ROBINSON-352780

\begin{tabular}{r|} 
Journal of Occupational and Organizational Psychology (2009), 00, 1-21 \\
(c) 2009 The British Psychological Society
\end{tabular}

\title{
Gender ratio, societal culture, and male and female leadership
}

\author{
Hetty van Emmerik ${ }^{\prime}$, Hein Wendt ${ }^{2}$ and Martin C. Euwema ${ }^{3}$ \\ 'Department of Organization and Strategy, Maastricht University, Maastricht, \\ The Netherlands \\ ${ }^{2}$ Hay Group B.V., Zeist, The Netherlands \\ ${ }^{3}$ Department of Organizational Psychology, University of Leuven, Leuven, Belgium
}

\begin{abstract}
Top management teams are worldwide largely composed of men, with relatively few female members. The gender ratio in top management is indicative of the position of women in management within the organization, as well as related to leadership behaviours of male and female managers. In the present study, the relative importance of societal culture, organizational, and individual characteristics in explaining leadership behaviours and the associations of gender and gender ratio with leadership behaviours are studied. Hypotheses are tested with multi-level analyses using a dataset with information from subordinates rating leadership behaviours of 12,546 managers in 437 organizations in 32 countries. The results show that in a three-level model (i.e. societal, organizational, and individual level) to explain leadership behaviours, differences in leadership behaviours are predominantly explained by individual differences, followed by organizational and societal differences. Further, after controlling for societal influences, a higher gender ratio (relatively more female managers), was positively associated with consideration and negatively related to initiating structure. Moreover, for male managers, there was a negative association between gender ratio and initiating structure, indicating that male managers in organizations with more female managers tend to engage less in initiating structure, whereas the leadership behaviours of female managers were not associated with the gender ratio.
\end{abstract}

Top management teams are worldwide largely composed of men, with female top managers being a minority. Gender ratio in top management, being the percentage of female and male managers in the team, is seen as an important indicator of both the percentage of women in management in the organization, as well as the styles in leadership behaviour in that organization of female and male managers (Kanter, 1977b; Tharenou, Latimer, \& Conroy, 1994). Kanter (1977b), theorizing in gender

Q1 * Correspondence should be addressed to Dr Hetty van Emmerik, Department of Organization and Strategy, Maastricht University, Postbus 616, 6200 MD Maastricht, The Netherlands (e-mail: h.vanemmerik@maastrichtuniversity.nl). 
JOOP 1135-14/10/2009-ROBINSON-352780

\section{Hetty van Emmerik et al.}

ratio within organizations and on particular proportions of women in predominantly male groups (for instance tokens), argued that groups with varying proportions of men and women differ qualitatively in dynamics and processes and that varying proportions reflect contacts between groups of employees as a function of their proportional representation in the system. It is therefore not surprising that there has been a notable interest in the study of gender, gender ratio, cultural processes, and their association with leadership behaviours. However, evidence of a strong association of gender, gender ratio, and cultural processes with leadership behaviours has not yet been conclusively established, although some studies indeed support this relationship (Dobbins \& Platz, 1986; Eagly \& Johannesen-Schmidt, 2001; Eagly \& Johnson, 1990; Konrad, Corrigall, Lieb, \& Ritchie, 2000; Lewis \& Fagenson-Eland, 1998). The current research on gender differences in leadership is overwhelmingly based on Western (mostly US based) data and there is a need to incorporate studies in non-Western cultures (Eagly, 2007; Eagly, Johannesen-Schmidt, \& Van Engen, 2003). We have a great deal to learn about the effects of gender, as it Q2 relates to international leadership (Scandura \& Dorfman, 2004). The GLOBE researchers (House, Hanges, Javidan, Dorfman, \& Gupta, 2004) found statistically significant, but not substantial, gender differences in respect to most of the GLOBE leadership dimensions (e.g. endorsement of team orientation as contributing to outstanding leadership). These differences are most prevalent in societies with larger cultural differences regarding male and female roles (Emrich, Denmark, \& Den Hartog, 2004). In line with this, Paris (2003) also found that gender differences in leadership are moderated by the level of gender egalitarianism in the societal culture. These are results in previous cross-cultural studies on gender and leadership and we agree with Dorfman, Hanges, and Brodbeck (2004) who conclude, based on the GLOBE study: 'we have a great deal to learn about gender differences across cultures' (p. 698).

In the present paper, we will use a three-level model to investigate the associations of societal, organizational, and individual characteristics with leadership behaviours. In the remainder of this section, we will elaborate on explaining leadership behaviours with the use of these three levels. Specifically, we will focus on the following issues. (1) Relative importance of societal culture, gender ratio, and individual characteristics (with a focus on gender and hierarchical position) in explaining leadership behaviours. (2) The association of gender and gender ratio with leadership behaviours. How does gender ratio at organizational level impact on the leadership behaviour of female and male managers? Does any impact of gender ratio interact with manager's gender after controlling for societal variables?.

The relation of gender and gender ratio with leadership behaviour will be addressed in a dataset using information from subordinates rating the leadership behaviours of 12,546 managers in 437 organizations in 32 countries. Many writers acknowledge the need to use worldwide samples, since most previous research on leadership has been conducted in Western countries. An enduring question remains regarding the extent to which these Western research findings are generalizable to other cultures (Javidan \& Dale, 2005). Given the state of knowledge, the variety of theoretical perspectives, the diversity of samples involved and the range of research designs used, an interesting avenue for research lies in examining the relative importance of individual, organizational, and societal level characteristics to explain leadership behaviours with a worldwide sample. 
JOOP 1135-14/10/2009-ROBINSON-352780

\section{Leadership}

Leadership refers to the abilities of an individual to influence, motivate, and enable others to contribute towards the effectiveness and success of organizations of which they are members (House et al., 2004). Although leadership behaviours can be conceptualized along various dimensions, much of their content can be captured using two constructs originating in the Ohio State approach to leadership (Stogdill, 1963, 1977). Consideration refers to friendly and interpersonally supportive supervisory behaviour (Yammarino, Dionne, Uk Chun, \& Dansereau, 2005). Consideration is described as a leadership behaviour that leaders use to create a supportive environment of warmth, friendliness, and helpfulness, for instance by being approachable, looking out for the welfare of the group, doing little things for subordinates, and giving advance notice of change (House, 1971; Judge, Piccolo, \& Ilies, 2004). Initiating Structure refers to task oriented and directive behaviour (Yammarino et al., 2005). This leadership behaviour is shown in an emphasis on assigning tasks, specifying procedures to be followed, clarifying expectations of subordinates, and scheduling work to be done (House, 1971).

Consideration and initiating structure are considered relatively independent leadership behaviours, such that leaders can be placed on a continuum from low to high on each of the two dimensions (Yammarino et al., 2005). Typically, these two types of leadership behaviour are measured by the Leader Behaviour Description Questionnaire (Stogdill, 1963) or with an adaptation of these scales. For instance, Brown, Ganesan, and Challagalla (2001) measured supervisory consideration with six items and initiation of structure with five items.

For the present study, consideration and initiating structure were chosen because both styles have been shown to have important main effects on numerous criteria that are considered to be fundamental indicators of effective leadership (Euwema, Wendt, \& Van Emmerik, 2007; Judge et al., 2004; Wendt, Euwema, \& Van Emmerik, 2009). Further, these types of leadership behaviours are particularly relevant to study gender issues because of the documented stereotypes which people hold concerning these styles (Eagly \& Johnson, 1990): men are believed to be more forceful, dominant, and motivated to master their environment and thus more inclined to use the initiating structure leadership behaviour. In contrast, women are believed to be more concerned with others (e.g. more kind, helpful, understanding) and more inclined to use the consideration leadership behaviour. Although these stereotypes of men and women are rather strong (Glick et al., 2004) and stable (Schein, 2007), there is limited support for these stereotypes in actual managerial behaviour. In their 1990 review, Eagly and Johnson did not find confirmation for the stereotypical image of men being more task oriented and females more relationship oriented. However, they did find, consistent with stereotypic expectations, that women tend to adopt a more democratic or participative style and a less autocratic or directive style than men. A review of the Q3 literature in 2000 by Van Engen and Willemsen (2001) confirmed these conclusions. In addition, Eagly et al. (2003) show that female managers, compared with male managers, use somewhat more transformative leadership and show more rewarding behaviour, whereas men are paying more attention towards mistakes by subordinates. Gardiner and Tiggemann (1999) observe that female managers are more oriented towards interpersonal leadership than man, however, only in female-dominated industries. It may be that women in male-dominated industries alter their relationship style to decrease perceived differences and stereotyping by male management. Alternatively, as suggested by Gardiner and Tiggemann, women in male-dominated 
JOOP 1135-14/10/2009-ROBINSON-352780

\section{Hetty van Emmerik et al.}

industries may have similar leadership styles to male managers because they are selected by them. It should be noted however, that all these conclusions are based on studies in Western societies; with an overwhelming majority US contexts. To generalize towards global leadership is too presumptuous. Most studies focusing on gender and societal culture in this field have included only a few countries (Diekman, Eagly, Mladinic, \& Ferreira, 2005). Gibson (1995), in a cross-cultural study in four countries, found in all countries that male managers emphasize more goal setting, whereas females focus more on interaction facilitation. Gibson did not find interactions between gender and culture. This might be due to the limited sample of four countries in her study, although Gibson labelled the four countries that were studied as two cultural dyads (Norway and Sweden vs. Australia and the USA). Generally, gender and context do interact in relation with expectations and actual behaviour of female and male managers (Eagly et al., 2003; Van Engen, Van der Leeden, \& Willemsen, 2001).

The literature on cross-cultural management shows that societal cultural differences have a pervasive influence on leadership behaviours (Hofstede, 2001; House et al., 2004; Van de Vliert, 2006; Wendt et al., 2009). As such, a considerable number of studies have shown that a societal culture helps to explain leadership behaviours (e.g. Brodbeck et al., 2000; Gerstner \& Day, 1994; Hofstede, 2001; House et al., 2004; Shaw, 1990; Smith, Peterson, \& Schwartz, 2002), though there also appears to be some important commonalities in leader behaviour across cultures (Brodbeck et al., 2000; Wendt et al., 2009). Moreover, societal cultures have an impact on organizational cultures, which in turn impact leader behaviour (Hofstede, 2001; Hofstede \& McCrae, 2004).

Although a large number of empirical studies have suggested associations of societal culture and organizational environment with leadership behaviours, most studies on leadership behaviours either have examined the relationship between societal culture and leadership behaviours or were concerned with what people think effective leadership looks like (e.g. Brodbeck et al., 2000; Javidan \& Dale, 2005; Parboteeah, Bronson, \& Cullen, 2005) or, conversely, have focused on organizational characteristics and leadership behaviours. For instance, the relationships between organizational culture and leadership behaviours have received considerable attention within specific countries (e.g. Skogstad \& Einarsen, 1999; Tsui, Zhang, Wang, Xin, \& Wu, 2006). The GLOBE study (House et al., 2004) on leadership was in this respect ground breaking, as this study systematically looks for differences in leadership due to culture, industry type, and organizational form (Brodbeck, Hanges, Dickson, Gupta, \& Dorfman, 2004). This worldwide study demonstrates the effects of both societal and organizational culture on leadership behaviours based on data from 62 countries. In the GLOBE study, perceived participative leadership is strongly negatively related to power distance as a cultural value, both at the societal and organizational level. In addition, participative leadership is strongly positively related to gender egalitarianism at societal and organizational level (Brodbeck et al., 2000). This study shows that organizational characteristics are embedded in societal characteristics. This might be particularly so for our focal point of interest; the gender ratio in management. Societal norms and practices reflect participation of women in management, as well as appropriate types of managerial behaviour (Gibson, 1995; Ridgeway, 2001). Therefore, it is essential to study the interaction of societal and organizational characteristics, if we want to achieve a better understanding of the complex relation between gender and leadership. 
JOOP 1135-14/10/2009-ROBINSON-352780

Relative importance of societal, organizational, and individual characteristics to explain leadership behaviours

Leadership behaviours are typically characteristics of individual managers or organizational leaders. Differences in leadership therefore are to a large extent explained by individual differences, such as (personality) traits, motives, skills, and competencies (Yukl \& Lepsinger, 2005). Leadership behaviours also depend on job characteristics, organizational design, and organizational culture. Organizational culture in turn is embedded in the societal culture. Indeed, there is ample evidence that societal culture has an impact on leadership behaviours (Smith, 2006). Nevertheless, the relative impact is a point of discussion in the field of intercultural leadership (Hofstede, 2006; Javidan, Dorfman, De Luque, \& House, 2006; Smith, 2006). Oyserman, Coon, and Kemmelmeier (2002), for example, argue that the individual variability (within societies) in 'individualism' is so large, that constructs at societal level are of little use and should be replaced by multi-level analyses. Matsumoto (2000) also emphasizes the relative limited influence of societal culture in explaining individual behavioural differences. We therefore can conclude that in understanding differences in leadership behaviours, we should include different levels, individual, organizational, and societal and most likely most variability is at the individual level.

There are many different definitions of culture but in essence, most of these definitions have in common that culture refers to patterns of beliefs and values that are manifested in practices, behaviours, and various artefacts shared by members of a nation or within an organization (Hofstede, 2001; House et al., 2004). Because organizations are embedded in the societal culture in which they exist, research on organizational level differences should examine both societal and organizational cultures. This is demonstrated, for example, in two well-known models in the field, Hofstede (2001) and GLOBE (House et al., 2004). Both models use a set of dimensions to describe cultural differences, at societal as well as at the organizational level.

Hofstede (2001) concludes that when both the societal and organizational levels are examined, organizational level differences are based on other elements than those that make up societal differences. For example, among societal cultures, comparing otherwise similar people, they found differences in values notwithstanding similarities in practices within organizations. Conversely, among organizational cultures, they found considerable differences in practices for people who held similar values. It can be argued that differences can be explained by the different places of socialization for values and for practices. Values are acquired in our early youth, mainly in the family, and in the neighbourhood and later at school. Organizational practices are learned through socialization at the workplace. Javidan et al. (2006) argue that the same cultural dimensions can be used to describe the organizational and societal values and practices and demonstrate this in the GLOBE project. Furthermore, the GLOBE project shows that in general organizational cultural differences are stronger predictors of leadership, compared with societal differences (Brodbeck et al., 2004). GLOBE does not present however the overall explained variance at societal and organizational value levels (Brodbeck et al., 2004). When comparing the relative importance of societal and organizational level characteristics, it can be argued that organizations may develop unique characteristics that can override the effects of the societal cultures within which they operate. For instance, Hattrup, Mueller, and Joens (2007) showed that multinational organizations often replicate existing routines and operating procedures in their foreign subsidiaries and by doing so, they provide for efficiency and control of 
JOOP 1135-14/10/2009-ROBINSON-352780

\section{Hetty van Emmerik et al.}

the facilities located in foreign countries. Thus, we can predict that the relative importance of organizational characteristics on leadership will be greater than characteristics of societal culture (House et al., 2004; Wendt et al., 2009).

Hypothesis 1: Differences in leadership behaviours are predominantly explained by individual differences, followed by organizational and societal differences.

\section{Gender, gender ratio, and leadership behaviours}

According to the gender perspective, differences in leadership behaviours of men and women originate in socialization processes, whereby individuals learn to conform to societal expectations about their gender role (see Carless, 1998; Fagenson, 1990). Similarly, social role theory (Eagly, 1989, 2007) proposes that individuals behave in accordance with societal expectations about their gender role. These expectations lead to gender differences in leadership behaviours. According to this gender perspective, the leadership behaviours of women include more consideration, whereas the leadership behaviours of men consist of more initiating structure (Carless, 1998; Eagly \& Johnson, 1990).

Empirical results to support gender differences in leadership behaviours are mixed and few firm conclusions can be drawn (e.g. Burke \& Collins, 2001; Dobbins \& Platz, 1986; Eagly \& Johnson, 1990; Omar \& Davidson, 2001; Van Engen et al., 2001; Wood \& Eagly, 2002). There is a general agreement that women face more barriers to becoming leaders than men do, but there is less agreement about the differences or similarities in leadership behaviours (Eagly \& Johannesen-Schmidt, 2001). Some studies have found gender differences in leadership behaviours, whereas other research has pointed to their absence (see Lewis \& Fagenson-Eland, 1998). The metaanalytic review by Dobbins and Platz (1986) indicated that male and female leaders engaged in equal amounts of initiating structure and consideration. The study of Konrad et al. (2000) showed that women attached greater importance to prestige and challenge. These job attributes seem more consistent with masculine than with feminine preferences. The male managers in the study of Lewis and Fagenson-Eland (1998) described themselves as being higher in initiating structure behaviour than did female leaders. The most recent meta-study (Eagly, 2007; Eagly et al., 2003) shows small, systematic differences in male and female leadership behaviours. Women are more transformational and more rewarding in their leadership, whereas men use more initiating structure and show more laissez-fair leadership. These conclusions are based on a vast majority of studies in Western, mostly US-based studies. Validation across societies is necessary.

In addition to the importance of societal culture and gender, an important factor is the gender ratio in the organization. Kanter (1977a) showed in her seminal work negative consequences of women's underrepresentation, both for women, as well for the organizational leadership culture. She therefore advocated a stronger numerical representation of women in management. Ever since, the proportion of women in managerial positions has attracted attention as one of the structural properties that may affect leadership behaviour, as well as organizational performance (Desvaux, DevillardHoellinger, \& Baumgarten, 2007). For instance, Berdahl and Anderson (2005) outline a dominant norms model that addresses how group composition based on other characteristics (e.g. ethnic or cultural) determines a variety of norms and structures that define groups. In the present study, we focus on its application to gender composition 
JOOP 1135-14/10/2009-ROBINSON-352780

and leadership behaviours. What does gender ratio imply for the choice of leadership behaviours? Female managers can be expected to be more likely to adopt men's preferences in leadership behaviour than vice versa, since women are more able and motivated to do so (Berdahl \& Anderson, 2005). Since women more often operate in male-dominated environments, they are thought to be better able to understand and operate in organizations where they belong to the minority.

The present study aims to assess whether working in an environment with different gender ratios is associated with different leadership behaviours after controlling for cultural influences. Based on Eagly and Johnson's (1990) meta-analysis, we hypothesize a direct association between gender ratio (relatively more female managers) and leadership behaviours beyond cultural influences and a moderating role of gender ratio on the relationship between gender and leadership behaviours.

\begin{abstract}
Hypothesis 2: After controlling for cultural influences, gender ratio will be related to leadership behaviour; a higher gender ratio (relatively more women), is positively related to consideration and negatively related to initiating structure.

Hypothesis 3: After controlling for cultural influences, gender ratio will moderate the relationship between gender and leadership behaviours. A higher percentage of women in management is associated with less initiating structure and more consideration by male managers (3a) and by female managers (3b).
\end{abstract}

\title{
Method
}

\section{Data and sample}

This study used data from the database of a worldwide operating consulting firm (Hay Group). The original dataset contains multi-actor data of managers and their subordinates within 473 organizations for a wide range of industries and services, both public and private. Data collection were part of the assessment of management training programmes within each of the organizations and this guaranteed a response rate of close to $100 \%$. For the present study, we selected only those countries with available scores on the cultural dimensions of Hofstede (2001) and all respondents with missing data were excluded. After this selection, in total there was information on the leadership behaviours of 12,546 managers ( $73 \%$ men and $27 \%$ women) as rated by their subordinates in 437 organizations in 32 countries.

\section{Measures}

Leadership behaviours

The items to measure the two dependent variables (i.e. types of leadership behaviour) were adapted from the original scales of the Ohio State Leadership Studies (Stogdill, 1963). The five items to measure consideration were: (1) frequently demonstrates concern for employees, (2) relies on what he/she learns through personal contact with employees to use each person's talent most effectively, (3) works hard to ease tensions whenever they arise in a work-group, (4) encourages employees to talk to him/her about personal problems, and (5) devotes a great deal of time to employees' job security and fringe benefits. Alpha was .81 . The items to measure initiating structure were: (1) supervises employees very closely, (2) expects his/her employees to follow instructions precisely, (3) requires employees to submit detailed reports of their 
JOOP 1135-14/10/2009-ROBINSON-352780

\section{Hetty van Emmerik et al.}

activities, (4) expects to carry out instructions immediately, and (5) makes most decisions for employees. Alpha was .79. All items used Likert-type scales, with answers ranging from $\mathrm{A}$ to $\mathrm{F}$, with on the extreme poles the alternative answers. For example, 'My manager rarely demonstrates concern for subordinates' (A) versus 'My manager frequently demonstrates concern for subordinates' (F). An average of five employees (i.e. direct subordinates of the manager) rated their manager's leadership behaviour. We examined the justification for aggregating subordinates' responses to assess the leadership behaviours of their managers by comparing the proportion of variance in the leadership behaviours variables that is accounted for by the aggregate level (i.e. the managerial level). This is the ICC (1) and is calculated as the ratio of the betweengroup variance to the total variance. In the present study, ICC (1) for consideration was $.33(p<.01)$ and for initiating structure $.26(p<.01)$. A significant ICC (1) value is commonly interpreted as a justification for aggregation to the group level and a range Q3 of 0.00-0.50 for ICC (1) has been reported adequate (James, 1982; see Chen, Lam, Naumann, \& Schaubroeck, 2005).

\section{Societal culture}

To assess the cultural influences at societal level, we used the scores of Hofstede's cultural dimensions (Hofstede, 2001; Hofstede \& McCrae, 2004). We choose Hofstede's original model, as this is a well-known and often referred to model, which is more parsimonious than others, for example, the GLOBE model with nine cultural dimensions, or Schwartz' model with seven dimensions. Also, our sample of societies had a good overlap with the societies in Hofstede's model. Finally, Hofstede's most used and least criticized dimensions, individualism, and power distance, correspond conceptually and empirically with GLOBE's in-group collectivism and power distance (Javidan et al., 2006). We used the original four dimensions: (1) power distance; the degree of equality, or inequality, between people in the country's society. For instance, low power distance indicates that a society stresses equality and opportunity for everyone. (2) Individualism; the degree a society reinforces individual or collective, achievement, and interpersonal relationships. For instance, low individualism is typical for societies with a more collectivist nature with close ties between individuals. (3) Masculinity; the degree a society reinforces traditional masculine work-role models of male achievement, control, and power. High masculinity is indicative for a high degree of gender differentiation. (4) Uncertainty avoidance; the level of tolerance for uncertainty and ambiguity within a society. High uncertainty avoidance creates a ruleoriented society that institutes laws, rules, regulations, and controls in order to reduce the amount of uncertainty.

\section{Gender, education, and hierarchical position}

At the individual level, we measured gender, educational level, and hierarchical level of each manager. We coded gender as 1 for females and 0 for males and we used the percentage as the gender ratio. We asked managers to indicate their educational level on a five-point scale: 1 'No secondary school', 2 'Secondary school graduate', 3 'College level education without degree', 4 'University graduate (first degree)', and 5 'Advanced degree'. To assess hierarchical level of the respondent, the managers were asked to indicate their hierarchical level on a six-point scale: 1 'Entry-level Individual 
JOOP 1135-14/10/2009-ROBINSON-352780

Contributor', 2 'Mid-level Individual Contributor', 3 'Senior-level Individual Contributor', 4 'First-level Manager', 5 'Mid-level Manager', and 6 'Senior-level Manager'.

\section{Gender ratio and structure}

At the organizational level, we measured two structural properties by aggregating the respective individual level variables. First, gender ratio of the managers within the organization was operationalized as the percentage of women within managerial levels. Second, we used the number of hierarchical levels as an indicator for hierarchical structuring of the organization, since we can expect that gender ratio and hierarchical level are associated with each other.

\section{Language issues}

Language issues are always a major concern in cross-cultural studies (Van de Vijver \& Tanzer, 2004). Accordingly, the items were all translated from English into most of the languages of the participating countries by native speakers, using the so-called application mode of translation (Van de Vijver \& Tanzer, 2004). With this method, it is implicitly assumed that the underlying construct is appropriate for each cultural group and that a simple, straightforward translation will suffice to derive an instrument that measures the same construct in the target group. The translators (consultants) were trained in the concepts and were familiar with the societies' culture; therefore, their translations represent the concepts adequately.

\section{Measurement equivalence across countries}

In every cross-cultural study also the question as to whether test scores obtained in different populations can be interpreted in the same way across these populations has to be dealt with (Scandura \& Dorfman, 2004; Van de Vijver \& Tanzer, 2004). Construct bias may occur if the construct measured is not identical across the cultural clusters used in the present study. Accordingly, to examine invariance of parameters, we tested different models following the suggestions of Byrne (2001). Since 32 countries is a very large number to compare and sample size did not always meet the minimum requirements for structural equation modelling, we grouped countries in 10 clusters indicated in the GLOBE study (House et al., 2004).

First, as a preliminary step in testing for invariance across groups, we tested for the validity of the two leadership behaviour factors (i.e. consideration and initiating structure) across the clusters simultaneously. The fit of this model provided the baseline value against which a model with constraints was compared. Next, we tested a model where the parameters were specified as being invariant (i.e. equivalent) across the cultural clusters. This model specified that all 10 -factor loadings, all 10 -factor error variances, the covariance of the two factors, and the two error covariances of the factors to be constrained equal across cultural clusters. The fit of the baseline model for the cultural clusters was considered adequate (e.g. RMSEA $=.03$, GFI $=.94, \mathrm{CFI}=.88$ ) although a statistically significant chi-squared value $(p<.01)$ of $17,709.56(d f=340)$ across the groups was found. Several authors suggest that the chi-squared test is not a good indicator of model fit when the sample size is as large as is the case in the present study because small and unimportant departures from the null hypothesis are almost certain to be detected (Byrne, 2001; Yin \& Fan, 2003). Therefore, the results of chi-squared test were not considered critical in evaluating model fit for this study. 
JOOP 1135-14/10/2009-ROBINSON-352780

\section{Hetty van Emmerik et al.}

The second model tested was the model with the constraints. A significant chi-squared value was found $18,881.21(d f=421)$. To evaluate the invariance hypothesis from a more practical perspective, the descriptive model fit indices associated with the models with different invariance constraints were inspected. It is expected that invariance will be reflected in the descriptive model fit indices because constraints on parameter estimates lead to poorer model fit. It turned out that the descriptive fit did not change much (RMSEA $=.03, \mathrm{GFI}=.94$, and $\mathrm{CFI}=.87$ ). In general, a GFI value close to 1.00 is being indicative of good fit. A value of the RMSEA of about .05 indicates a close fit of the model and a value of $>.90$ for the CFI is representative of a good fit (Byrne, 2001). Thus, the results of the fit indices indicated that the invariance constraints on pattern coefficients did not cause any appreciable worsening in model fit. This supports the conclusion that the factor pattern coefficients are reasonably invariant across the cultural clusters (see Yin \& Fan, 2003).

\section{Results}

Table 1 presents means, standard deviations, and correlation coefficients for all measures included in the study. Table 2 presents a summary of the research variables by country.

The results in the correlation table must be interpreted with caution: with this large sample size (very) small correlations between variables can be statistically significant even if they have no real practical significance. However, when we focus on the associations important for the analyses we can see that consideration and initiating structure are negatively correlated $(r=-.19, p<.01)$. In addition, both types of leadership behaviours are positively correlated with gender. Females use more consideration than male managers do $(r=.14, p<.01)$ and surprisingly, also slightly more initiating structure $(r=.05, p<.01)$. Further, it is worth noticing that the percentage of female managers is significantly related to all four cultural dimensions. The percentage of female managers is higher in more individualistic $(r=.21, p<.01)$ and more masculine cultures $(r=.18, p<.01)$. The percentage of female managers is lower in cultures scoring high on uncertainty avoidance $(r=-.20, p<.01)$ and scoring high on power distance $(r=-.15, p<.01)$. Further, the associations between the variables are low to moderate, although most of them are significant, which is not surprising with the large sample size. Correlations that were moderate or strong (above .25) and therefore potentially useful/meaningful, were relatively fewer in number. Worth noticing are the relatively strong relations between societal individualism and initiating structure $(-.36)$ and societal uncertainty avoidance and initiating structure (+.23) (see also, Wendt et al., 2009). Strong intercorrelations also are found between some of the measures of the cultural dimensions. For instance, in Table 2, we can see high intercorrelations between power distance and uncertainty avoidance $(r=.39)$, between individualism and uncertainty avoidance $(r=.50)$ and between individualism and power distance $(r=-.83)$. Two comments should be made in this regard. First,

Q3 Hofstede (1980), whose scales are adopted here, found similar high intercorrelations between subscales. For example, the high negative correlation between power distance and individualism is $(r=-.83)$ is a replication of the high negative correlation $(r=-.67)$ between individualism and power distance in the original work of Q3 Hofstede (1980). Second, we should note that correlations between the Hofstede Q3 dimensions are typically around .60 to .80 (Harzing, 2006). 
JOOP 1135-14/10/2009-ROBINSON-352780

Female and male leadership II

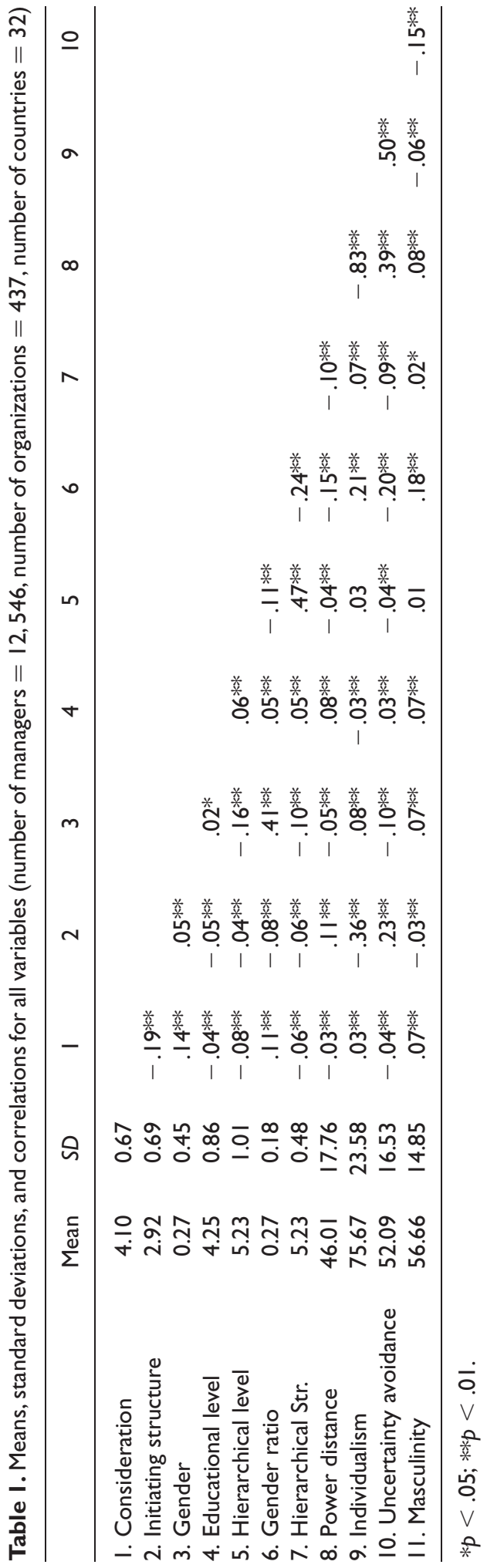


JOOP 1135-14/10/2009-ROBINSON-352780

12 Hetty van Emmerik et al.

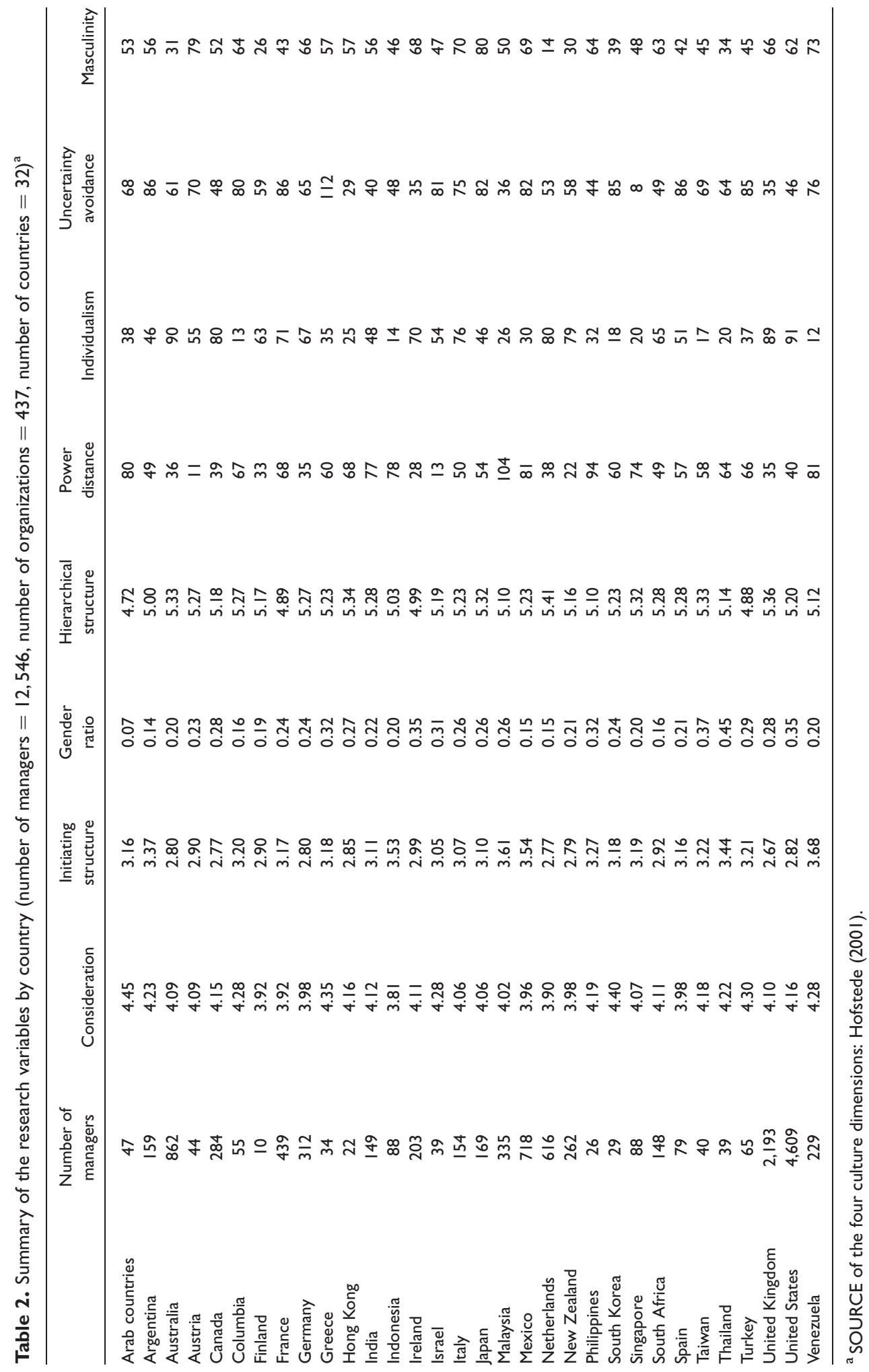


JOOP 1135-14/10/2009-ROBINSON-352780

Testing the relative importance of different levels in explaining leadership behaviours with multi-level partitioning of variance

Hypothesis 1 predicted that differences in leadership behaviours are predominantly explained by individual differences, followed by organizational and societal differences. To test this hypothesis, the distribution of variance of both leadership behaviours in the empty multi-level models was examined with the xtmixed procedure for fitting linear mixed models procedure of STATA 9.0. The empty multi-level model allowed us to partition the total variability in leadership behaviours into three distinct components representing the variability in the level 1, level 2, and level 3 units (Raudenbush, Bryk, \& Congdon, 2007). Accordingly, we used the random effects parameters of the null model to compute the distribution of the explained variance. For example, for initiating structure this is: the proportion of variance at level 1 , this is the $\operatorname{var}($ residual $) /(\operatorname{var}($ residual $)+\operatorname{var}($ organization $)+\operatorname{var}($ countries $))=.36 /(.36+$ $.05+.05)=.79(=79 \%)$.

For the proportion of variance at level 2 , this is $\operatorname{var}($ organization $) /(\operatorname{var}($ residual $)+$ $\operatorname{var}($ organization $)+\operatorname{var}($ countries $))=.05 /(.36+.05+.05)=.11(11 \%)$. For the proportion of variance at level 3 , this is $\operatorname{var}($ countries $) /(\operatorname{var}($ residual $)+\operatorname{var}($ organization $)+$ $\operatorname{var}($ countries $))=.05 /(.36+.05+.05)=.10(10 \%)$. Table 3 shows that the distribution of variance for consideration is for $93 \%$ at the individual level, $5 \%$ at the organizational level, and for $2 \%$ at the society level. The distribution of variance of initiating structure is $79 \%$ at the individual level, $11 \%$ at the organizational level, and $10 \%$ at the society level. Thus, Hypothesis 1 is supported.

Table 3. Distribution of explained variance for the three levels in the empty model (number of managers $=12,546$, number of organizations $=437$, number of countries $=32$ )

\begin{tabular}{lcc}
\hline & \multicolumn{2}{c}{ Dependent variable } \\
\cline { 2 - 4 } & Consideration (\%) & Initiating structure (\%) \\
\hline Level & 93 & 79 \\
Manager & 5 & 11 \\
Organization & 2 & 10 \\
Country & 100 & 100 \\
Total & & \\
\hline
\end{tabular}

Note. The distribution of explained variance for the three levels is based on the explained variance $R^{2}$ for the empty model of consideration and initiating structure; $* p<.05, * * p<.01$.

\section{Testing direct effects and the moderating role of gender ratio with three-level} mixed-effects regression analyses

To test Hypotheses 2 and 3, we performed two three-level mixed-effects regression analyses with the subordinates reported leadership behaviours of the managers as the dependent variables. For these analyses, we also used the xtmixed procedure of STATA 9.0 since this command is appropriate for mixed model estimation in general, including Q3 cross-sectional applications and can handle three-level data (Albright, 2007). In this type of multi-level analyses, intercepts and regression slopes may vary randomly across societies. The variables were entered in three steps. The results of these analyses are reported in Table 4 . The average score for consideration, reflected in the intercept term, is $4.09(p<.01)$ and for initiating structure $3.10(p<.01)$. After the estimation of the 
JOOP 1135-14/10/2009-ROBINSON-352780

14 Hetty van Emmerik et al.

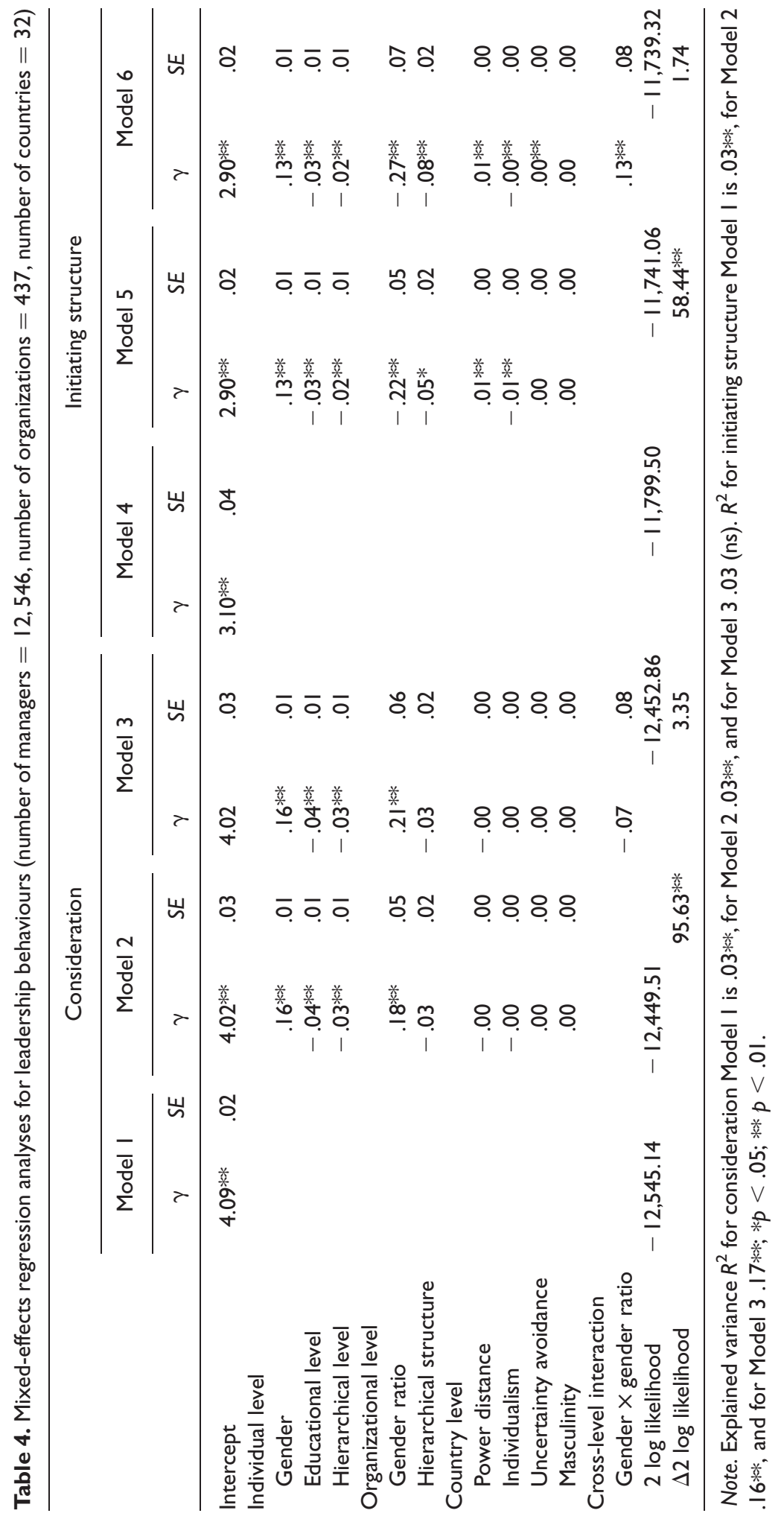


JOOP 1135-14/10/2009-ROBINSON-352780

empty model (see Models 1 and 4 ) in Step 2 the main effects were entered (see Models 2 and 5). In Step 3, the cross-level interactions were added (see Models 3 and 6). As noted above, due to the large sample size the results have to be interpreted with caution. In fact, there is a surprising number of '.00's in the lower left corner of Table 4 due to very small coefficients, pointing at a lack of direct effects of country level cultural dimensions on consideration.

Hypothesis 2 predicted that after controlling for cultural influences, gender ratio would be associated with leadership behaviour; a higher gender ratio (relatively more female managers) will be positively associated with consideration and negatively related to initiating structure. Model 2 in Table 4 shows that gender ratio (relatively more female managers) is indeed positively associated with consideration $(\gamma=.18, p<.01)$ and negatively associated with initiating structure $(\gamma=-.22, p<.01)$. Therefore, Hypothesis 2 is supported.

Hypothesis 3 predicted that beyond the influence of culture, gender ratio will moderate the relationship between gender and leadership behaviours. A higher percentage of women in management are associated with less initiating structure and more consideration by male managers ( $3 a$ ) and by female managers ( $3 b$ ). Separate mixed-effects regression analyses for initiating structure for male and female managers shows that for female managers there is no significant relationship between gender ratio and initiating structure. For male managers, there is a negative association between gender ratio and initiating structure $(\gamma=-.19, p<.01)$. Thus, entering the interaction term in the analysis shows that the gender ratio effect only holds for the male managers and not for the female managers: male managers in organizations with more female managers tend to engage in less initiating structure. There is no relation found between gender ratio and consideration by either male of female managers. Therefore, Hypothesis $3 \mathrm{a}$ is confirmed for initiating structure and not for consideration: with a higher percentage of female managers, male managers indeed engage less in initiating structure. We do not find support for Hypothesis $3 b$.

\section{Discussion}

The results of this study show that using a three-level model to explain leadership behaviours, differences in leadership behaviours are predominantly explained by individual differences, followed by organizational and societal differences. The distribution of variance of initiating structure is $79 \%$ at the individual level, $11 \%$ at the organizational level, and $10 \%$ at the societal level. The distribution of variance of consideration is $93 \%$ at the individual level, $5 \%$ at the organizational level, and $2 \%$ at the societal level. Further, after controlling for societal influences, a higher gender ratio (relatively more female managers) was positively associated with consideration and negatively related to initiating structure. Moreover, for male managers, there was a negative association between gender ratio and initiating structure, indicating that male managers in organizations with more female managers tend to engage less in initiating structure, whereas the leadership behaviours of female managers were not associated with the existing gender ratio in an organization.

This study on worldwide leadership has several unique features. First, the large dataset in which subordinates evaluate the actual leader styles of female and male managers in 32 countries offers new information on these styles across cultures. Second, the three-level analyses offer a more comprehensive understanding of the associations of 
JOOP 1135-14/10/2009-ROBINSON-352780

\section{Hetty van Emmerik et al.}

gender with leadership. Third, leadership behaviours are measured through the perception of the subordinates (direct reports) of the manager, offering a more realistic assessment of this behaviour compared with self-reported measures. We used an average of five subordinates evaluating the managers' behaviour, with a high inter-rater reliability.

As the results of this study show, increasing the proportion of female managers does have an impact on perceived male leadership behaviours (i.e. less initiating structure by male managers), however not on perceived female leadership behaviours. Thus, controlling for societal cultural differences, gender ratio has a negative association with initiating structure for male managers. This implies that indeed more 'feminine leadership behaviour' is realized when more women are in managerial positions. Consideration is used globally more than initiating structure and the prevalence of consideration becomes relatively stronger for male managers in case of more female managers. With a stronger relative use of consideration, one can conclude this reflects a more 'feminine approach'. Interestingly, we find in our worldwide study that both leadership behaviours are used more by female leaders. This contrasts with the classic stereotypes of men being 'tough' versus women being 'sociable' (Schein, 2007) and supports the idea that female managers put more effort into their leadership, compared with men (Eagly, 2007).

Another interesting observation in this study is the relation between leadership behaviours and hierarchical level. We find negative correlations, implicating that managers at higher levels in the organizations use (slightly) less consideration and also less initiating structure. This supports results from the meta-analytic study by Lowe, Kroeck, and Sivasubramaniam (1996) that at higher levels managers use all types of leadership behaviours less, compared with lower organizational levels.

Clearly, one of the strengths of this study is the large sample size of 12,546 managers in 437 organizations in 32 countries. However, this study necessitates that the results should be interpreted with a certain degree of caution, since a Western culture-oriented consultancy firm collected the data. Respondents with an international or even Western orientation may have been overrepresented; moreover, one-third of the dataset comes from the USA.

As several authors have already suggested (e.g. Blum, Fields, \& Goodman, 1994; Fagenson, 1990), the experiences of female managers may be influenced not only by their gender and the attitudes of those in power, but also by the organizational context, including a firm's history, industry, and policies. In the present study, we only used a few variables. However, from a contingency perspective, it may be important to broaden this type of research to other characteristics that are important to understand leadership behaviours in different cultures. Clearly, other variables should be considered or controlled for, including: modernity, economic wealth, population size, political system, and other socio-economic characteristics (Sivakumar \& Nakata, 2001). An interesting avenue for research lies in identifying those circumstances.

In the present study, we focused on the importance of organizational and individual characteristics (i.e. gender ratio and gender). This is important because characteristics of organizations appear to predict a substantial portion of the variation in the explanations of leadership behaviours. Moreover, as previous research showed (Blum et al., 1994), organizational characteristics influence the percentage of management positions filled by women, at least as much as do the beliefs and attitudes of members within organizations. Therefore, the results of our study are important for diversity management. Results show the effect of an increase of female managers on 
JOOP 1135-14/10/2009-ROBINSON-352780

organizational culture, in particular on male leadership. A higher percentage of female managers contributes to less initiating structure by male managers.

The results of this study can be especially useful for globally operating organizations and organizations considering the decision to transfer management practices from one cultural setting to another. Our results indicate that the percentage of female managers in organizations does have a substantially larger impact on leadership behaviours, than societal culture. Societal cultural differences are often emphasized in discussions about international cooperation, mergers, and other forms of international business. Particularly, problems in cooperation and failures, for example in mergers, are often attributed to different leadership behaviours in the partner countries. Given our results, these differences might be overstated. The societal cultural effects on two dominant leadership behaviours are less than often presented. This might also help in training and developing international managers, to overcome stereotypical thinking about leadership behaviours.

\section{References}

Adler, N. J., Brody, L. W., \& Osland, J. S. (2001). Going beyond twentieth century leadership: A CEO develops his company's global competitiveness. Cross Cultural Management: Q4 An International Journal, 8(3/4), 11-34.

Berdahl, J. L., \& Anderson, C. (2005). Men, women, and leadership centralization in groups over time. Group Dynamics, 9(1), 45-57.

Blum, T. C., Fields, D. L., \& Goodman, J. S. (1994). Organization-level determinants of women in management. Academy of Management Journal, 37(2), 241-268.

Brodbeck, F. C., Frese, M., Akerblom, S., Audia, G., Bakacsi, G., Bendova, H., et al. (2000). Cultural variation of leadership prototypes across 22 European countries. Journal of Occupational and Organizational Psychology, 73(1), 1-29.

Brodbeck, F. C., Hanges, P. J., Dickson, M. W., Gupta, V., \& Dorfman, P. W. (2004). Societal culture and industry sector influences on organizational culture. In R. J. House, P. J. Hanges, M. Javidan, P. Dorfman, \& V. Gupta (Eds.), Culture, leadership, and organizations. The GLOBE study of 62 societies (pp. 654-668). London: Sage.

Brown, S. P., Ganesan, S., \& Challagalla, G. (2001). Self-efficacy as a moderator of informationseeking effectiveness. Journal of Applied Psychology, 86(5), 1043-1051.

Burke, S., \& Collins, K. M. (2001). Gender differences in leadership styles and management skills. Women in Management Review, 16(5), 244-257.

Byrne, B. M. (2001). Structural equation modeling with Amos. Mahwah, NJ: Erlbaum.

Carless, S. A. (1998). Gender differences in transformational leadership: An examination of superior, leader, and subordinate perspectives. Sex Roles, 39(11/12), 887-902.

Chen, X.-P., Lam, S. S. K., Naumann, S. E., \& Schaubroeck, J. (2005). Group citizenship behaviour: Conceptualization and preliminary tests of its antecedents and consequences. Management and Organization Review, 1(2), 273-300.

Desvaux, G., Devillard-Hoellinger, S., \& Baumgarten, P. (2007). Women matter. Gender diversity, a corporate performance driver. Paris: McKinsey \& Company.

Diekman, A. B., Eagly, A. H., Mladinic, A., \& Ferreira, M. C. (2005). Dynamic stereotypes about women and men in Latin America and the United States. Journal of Cross-Cultural Psychology, 36, 209-226.

Dobbins, G. H., \& Platz, S. J. (1986). Sex differences in leadership: How real are they? Academy of Management Review, 11(1), 118-127.

Dorfman, P. W., Hanges, P. J., \& Brodbeck, F. C. (2004). Leadership and cultural variation: The identification of culturally endorsed leadership profiles. In R. J. House, P. J. Hanges, M. Javidan, 
JOOP 1135-14/10/2009-ROBINSON-352780

18 Hetty van Emmerik et al.

P. W. Dorfman, \& V. Gupta (Eds.), Culture, leadership, and organizations. The GLOBE study of 62 societies (pp. 669-720). London: Sage.

Eagly, A. H. (1989). Sex differences in social behavior: A social-role interpretation. Hillsdale, NJ: Erlbaum.

Eagly, A. H. (2007). Female leadership advantage and disadvantage: Resolving the contradictions. Psychology of Women Quarterly, 31, 1-12.

Eagly, A. H., \& Johannesen-Schmidt, M. C. (2001). The leadership styles of women and men. Journal of Social Issues, 57(4), 781-797.

Eagly, A. H., Johannesen-Schmidt, M. C., \& Van Engen, M. L. (2003). Transformational, transactional, and laissez-faire leadership styles: A meta-analysis comparing women and men. Psychological Bulletin, 129(4), 569-591.

Eagly, A. H., \& Johnson, B. T. (1990). Gender and leadership style: A meta-analysis. Psychological Bulletin, 108(2), 233-256.

Emrich, C. G., Denmark, F. L., \& Den Hartog, D. N. (2004). Cross-cultural differences in gender egalitarianism. In R. J. House, P. J. Hanges, M. Javidan, P. W. Dorfman, \& V. Gupta (Eds.), Culture, leadership, and organizations (pp. 343-394). Thousand Oaks, CA: Sage.

Euwema, M., Wendt, H., \& Van Emmerik, H. (2007). Leadership styles and group organizational citizenship behavior across cultures. Journal of Organizational Behavior, 28(8), 1035-1057.

Fagenson, E. A. (1990). At the heart of women in management research: Theoretical and methodological approaches and their biases. Journal of Business Ethics, 9, 267-274.

Gardiner, M., \& Tiggemann, M. (1999). Gender differences in leadership style, job stress and mental health in male- and female-dominated industries. Journal of Occupational and Organizational Psychology, 72(3), 301-315.

Gerstner, C. R., \& Day, D. V. (1994). Cross-cultural comparison of leadership prototypes. Leadership Quarterly, 5(2), 121-134.

Gibson, C. B. (1995). An investigation of gender differences in leadership across four countries. Journal of International Business Studies, 26(2), 255-279.

Glick, P., Lameiras, M., Fiske, S. T., Eckes, T., Masser, B., Volpato, C., et al. (2004). Bad but bold: Ambivalent attitudes toward men predict gender inequality in 16 nations. Journal of Personality and Social Psychology, 86(5), 713-728.

Hattrup, K., Mueller, K., \& Joens, I. (2007). The effects of nations and organizations on work value importance: A cross-cultural investigation. Applied Psychology: An International Review, 56(3), 479-499.

Hemphill, J. F. (2003). Interpreting the magnitudes of correlation coefficients. American Q4 Psychologist, 58(1), 78-79.

Hofstede, G. (2001). Culture's consequences. Comparing values, behaviors, institutions, and organizations across nations. Thousand Oaks, CA: Sage.

Hofstede, G. (2006). What did GLOBE really measure? Researchers' minds versus respondents' minds. Journal of International Business Studies, 37, 882-896.

Hofstede, G., \& McCrae, R. R. (2004). Personality and culture revisited: Linking traits and dimensions of culture. Cross-Cultural Research, 38(1), 52-88.

House, R. J. (1971). A path goal theory of leader effectiveness. Administrative Science Quarterly, 16(3), 321-339.

House, R. J., \& Dessler, G. (1974). The path goal theory of leadership: Some post-hoc and a priori tests. In J. G. Hunt \& L. L. Larson (Eds.), Contingency approaches to leadership (pp. 29-55).

Q4 Carbondale, IL: Southern Illinois University Press.

House, R. J., Hanges, P. J., Javidan, M., Dorfman, P. W., \& Gupta, V. (2004). Culture, leadership, and organizations. The GLOBE study of 62 societies. London: Sage.

Javidan, M., \& Dale, E. C. (2005). Leadership across cultures: A study of Canadian and Taiwanese executives. Management International Review, 45(1), 23-44.

Javidan, M., Dorfman, P. W., De Luque, M. S., \& House, R. J. (2006). In the eye of the beholder: Cross cultural lessons in leadership from project GLOBE. Academy of Management Perspectives, 20(1), 67-90. 
JOOP 1135-14/10/2009-ROBINSON-352780

Judge, T. A., Piccolo, R. F., \& Ilies, R. (2004). The forgotten ones? The validity of consideration and initiating structure in leadership research. Journal of Applied Psychology, 89(1), 36-51.

Kanter, R. M. (1977a). Men and women of the corporation. New York: Basic Books.

Kanter, R. M. (1977b). Some effects of proportions on group life: Skewed sex ratios and responses to token women. American Journal of Sociology, 82, 965-990.

Konrad, A. M., Corrigall, E., Lieb, P., \& Ritchie, J. E. (2000). Sex differences in job attribute preferences among managers and business students. Group and Organization Management, 25(2), 108-131.

Lewis, A. E., \& Fagenson-Eland, E. A. (1998). The influence of gender and organization level on perceptions of leadership behaviors: A self and supervisor comparison. Sex Roles, 39(5/6), 479-502.

Lowe, K. B., Kroeck, K. G., \& Sivasubramaniam, N. (1996). Effectiveness correlates of transformational and transactional leadership: A meta-analytic review of the MLQ literature. Leadership Quarterly, 7(3), 385-425.

Matsumoto, D. (2000). Culture and psychology: People around the world. Belmont, CA: Wadsworth/Thomson Learning.

Omar, A., \& Davidson, M. J. (2001). Women in management: A comparative cross-cultural overview. Cross Cultural Management: An International Journal, 8(3/4), 35-67.

Oyserman, D., Coon, H. M., \& Kemmelmeier, M. (2002). Rethinking individualism and collectivism: Evaluation of theoretical assumptions and meta-analyses. Psychological Bulletin, 128(1), 3-72.

Parboteeah, K. P., Bronson, J. W., \& Cullen, J. B. (2005). Does national culture affect willingness to justify ethically suspect behaviors? A focus on the GLOBE national culture scheme. International Journal of Cross Cultural Management, 5(2), 123-138.

Paris, L. (2003). The effect of gender and culture on implicit leadership theories: A cross-cultural study. Las Cruces, NM: New Mexico State University.

Raudenbush, S., Bryk, A. S., \& Congdon, R. (2007). Proportion variance explained: Three-level models. Lincolnwood, IL: SSI Scientific Software.

Ridgeway, C. L. (2001). Gender, status, and leadership. Journal of Social Issues, 57(4), 637-655.

Scandura, T., \& Dorfman, P. (2004). Leadership research in an international and cross-cultural context. Leadership Quarterly, 15(2), 277-307.

Schein, V. E. (2007). Women in management: Reflections and projections. Women in Management Review, 22(1), 6-18.

Shaw, J. B. (1990). A cognitive categorization model for the study of intercultural management. Academy of Management Review, 15(4), 626-645.

Sivakumar, K., \& Nakata, C. (2001). The stampede toward Hofstede's framework: Avoiding the sample design pit in cross-cultural research. Journal of International Business Studies, 32(3), 555-573.

Skogstad, A., \& Einarsen, S. (1999). The importance of a change-centred leadership style in four organizational cultures. Scandinavian Journal of Management, 15(3), 289-306.

Smith, P. B. (2006). When elephants fight, the grass gets trampled: The GLOBE and Hofstede projects. Journal of International Business Studies, 37, 915-921.

Smith, P. B., Peterson, M. F., \& Schwartz, S. H. (2002). Cultural values, source of guidance, and their relevance to managerial behavior: A 47-nation study. Journal of Cross-Cultural Psychology, 33, 188-208.

Stogdill, R. M. (1963). Manual for the leader behavior description questionnaire - form XII. Columbus, OH: Fisher College of Business, The Ohio State University.

Stogdill, R. M. (1977). Handbook of leadership: A survey of theory and research. New York: Free Press.

Tharenou, P., Latimer, S., \& Conroy, D. (1994). How do you make it to the top? An examination of influences on women's and men's managerial advancement. Academy of Management Journal, 37, 899-931. 
JOOP 1135-14/10/2009-ROBINSON-352780

20 Hetty van Emmerik et al.

Tsui, A. S., Zhang, Z. X., Wang, H., Xin, K. R., \& Wu, J. B. (2006). Unpacking the relationship between CEO leadership behavior and organizational culture. Leadership Quarterly, 17(2), 113-137.

Van de Vijver, F., \& Tanzer, N. K. (2004). Bias and equivalence in cross-cultural assessment: An overview. Revue Europeenne de Psychologie Appliquee, 54(2), 119-135.

Van de Vliert, E. (2006). Autocratic leadership around the globe: Do climate and wealth drive leadership culture? Journal of Cross-Cultural Psychology, 37(1), 42-59.

Van Engen, M. L., Van der Leeden, R., \& Willemsen, T. M. (2001). Gender, context and leadership styles: A field study. Journal of Occupational and Organizational Psychology, 74(5), 581-598.

Wendt, H., Euwema, M., \& Van Emmerik, I. H. (2009). Leadership and team cohesiveness across cultures. Leadership Quarterly, 20(2), 358-370.

Wood, W., \& Eagly, A. H. (2002). A cross-cultural analysis of the behavior of women and men: Implications for the origins of sex differences. Psychological Bulletin, 128(5), 699-727.

Yammarino, F. J., Dionne, S. D., Uk Chun, J., \& Dansereau, F. (2005). Leadership and levels of analysis: A state-of-the-science review. Leadership Quarterly, 16(6), 879-919.

Yin, P., \& Fan, X. (2003). Assessing the factor structure invariance of self-concept measurement across ethnic and gender groups: Findings from a national sample. Educational and Psychological Measurement, 63(2), 296-318.

Yukl, G., \& Lepsinger, R. (2005). Why integrating the leading and managing roles is essential for organizational effectiveness. Organizational Dynamics, 34(4), 361-375.

Received 23 October 2008; revised version received 9 September 2009 